\title{
Being moved by nature in the Anthropocene: On the limits of the
}

\section{ecological sublime}

Marco Caracciolo

Ghent University

marco.caracciolo@ugent.be

Accepted version, please cite published article

\section{Abstract}

What does it mean to be moved by nature when human activities are dramatically reshaping landscapes and ecosystems around the globe? My article engages with this question in three steps: I start by rethinking the sublime as an affect that, since Romanticism, has marked Western attitudes toward the nonhuman. As a second step, I take the phrase "being moved" seriously by conceptualizing emotion materially, as a kinesthetic resonance linking human subjects to nonhuman realities. Third, I argue that, once this materialist account of emotion is in place, the climate crisis calls for an expansion of our affective engagement with the nonhuman in light of human societies' moral and material entanglement with the Earth's ecosystems. This embodied account lays the foundation for a reconceptualization of being moved as a fully embodied experience grounded in kinesthetic patterns of interaction with the world.

\section{Introduction}

Like artworks, natural landscapes have the capacity to elicit the emotion of "being moved" (see Cova \& Deonna, 2014): when taking in the spectacular coastline of Australia's Great Ocean Road, for instance, or the cliffs on the island of Kauai in the Hawaiian archipelago, it is easy to be moved by the grandeur of these sweeping vistas. According to Cova and Deonna (2014), we experience "being moved" in 
situations of human interaction in which positive core values - such as kindness or selflessness-are brought into play. What are the core values evoked by nonhuman landscapes, however, particularly as the distinction between man-made and natural environments becomes increasingly blurry? That is the central question tackled by this article, which examines the significance of emotional responses to natural phenomena in the so-called Anthropocene. Introduced by atmospheric scientist Paul Crutzen (2002), the term "Anthropocene" refers to the current geological era, which Crutzen sees as marked by the devastating impact of human activities on the Earth's climate and ecosystems. This impact makes it impossible to neatly differentiate natural and anthropic processes. I approach being moved by nature in three steps: I start by rethinking the sublime as an affect that, since Romanticism, has shaped Western attitudes toward nature. This reappraisal builds on Edmund Burke's deeply embodied and material account of the sublime, which I distinguish from the more idealistic and transcendental notion emerging after Burke, particularly in Immanuel Kant's wake. As a second step, I take the phrase "being moved" seriously by conceptualizing emotion materially, as a kinesthetic resonance linking human subjects to nonhuman realities. The phenomenologically grounded philosophy of David Abram and Maxine SheetsJohnstone provides key inspiration here. Third, I argue that, once this materialist account of emotion is in place, today's climate crisis calls for an expansion of our affective engagement with the nonhuman: the sublime can be part of our emotional repertoire, but only if it is complicated by feelings that point to constitutive human-nonhuman entanglement and highlight our moral responsibilities vis-à-vis the natural world.

My discussion suggests that philosophical debates on being moved should steer clear of problematic binaries, including both nature vs. humankind and mind vs. body, which continue structuring our understanding of emotional experience. Instead, it is imperative to take on board the embodied and kinesthetic dimension of being moved. A notable case of covert dualism that also downplays embodiment is Noel Carroll's (1993) conceptualization of "being moved by nature." Carroll engages 
with Allen Carlson's work on the aesthetics of nature-an account that Carlson developed in a series of articles published at the end of the 1970 s and in the 1980 s. $^{1}$ For Carlson, the appreciation of natural landscapes is tied to scientific knowledge about the natural world, so that-for example-we can derive pleasure from exploring a thick forest because we are aware of the ecosystemic relations that sustain this environment. Carroll does not deny that naturalistic knowledge may feed into appreciation of the natural environment, but he argues that it is not the only source of appreciation. Instead, he develops an "arousal model" centered on the emotional responses elicited by natural environments. These responses do not require specialized scientific knowledge, but only-in Carroll's words, who is here discussing the example of a majestic waterfall-"being human, equipped with the senses we have, being small and able to intuit the immense force, relative to creatures like us, of the roaring tons of water" (1993, p. 251). Carroll's subsequent discussion is cast in vaguely evolutionary terms. Drawing on Jay Appleton's seminal contribution to landscape aesthetics, The Experience of Landscape (1975), Carroll argues that "features of landscape like prospect and refuge may cause our humanly emotional responses to natural expanses in terms of the way they address our deep-seated, perhaps tacit, interests in the environment as a potential theatre of survival” $(1993$, p. 263). While Carroll does mention in passing that emotional engagement with nature may be partly shaped by culture, he tends to view it as a human universal.

Carroll's essay is a fine example of philosophy of art in the analytic tradition, but some of its assumptions are problematic: when scrutinized closely, Carroll's argument affirms a notion of being moved by nature that, far from being an evolutionary universal, is closely bound up with the cultural history of Western modernity. Many of his examples hover around vast or majestic natural landscapessuch as mountains and waterfalls - that would not look out of place in the work of canonical British Romantic poets like William Wordsworth or Percy Shelley. ${ }^{2}$ Carroll's remark on "being small and able to intuit the immense force" of a waterfall evokes the classical repertoire of the Romantic sublime, which 
foregrounds scalar disparity between the human and the nonhuman-especially when this disparity can be apprehended from a safe distance. Likewise, Carroll's comments on "standing barefooted amidst a silent arbor, softly carpeted with layers of decaying leaves" $(1993$, p. 245) bring to mind nature writing à la Henry Thoreau, with its vision of communion with nature. ${ }^{3}$ Like the Romantic investment in the aesthetics of the sublime, this vision is a response to the increasing separation between natural and human spheres that defines Western modernity.

Indeed, Carroll's repeated references to natural environments assume that the philosopher and his readers know what nature is and where it is to be found-plausibly, far from human settlements, in pristine landscapes untouched by civilization. But this binary separation has become increasingly difficult to endorse in the years since the publication of Carroll's essay. In an article titled "Twenty-Two Theses on Nature," Steven Shaviro offers the following first thesis:

We can no longer think of Nature as one side of a binary opposition. In an age of anthropogenic global warming and genetically modified organisms, not to mention Big Data and world-encompassing computing and communications networks, it makes no sense to oppose nature to culture, or a "state of nature" to human society, or the natural to the artificial. Human beings and their productions are not separate from Nature: they are just as "natural" as everything else. (2012, p. 205)

This is far from being a provocation advanced by Shaviro; it is the uncontroversial premise of extensive discussions in fields that range from anthropology to history, environmental philosophy, and literary studies. ${ }^{4}$ The Anthropocene is defined by what Dipesh Chakrabarty (2014) calls the "collision" of human and nonhuman histories, particularly the rise of global capitalism and geological and climatological transformations in the Earth system. Advanced industrial societies have entered the geological record by leaving a physical trace on our planet, through environmental degradation, species extinction, and the 
depletion of fossil fuels. Nature can no longer be neatly separated from human activity, and can no longer be appreciated from the safe distance presupposed by Carroll's argument and by the Romantic aesthetics of the sublime.

The discussion thus shifts from being moved by nature as a question of aesthetic pleasure to being moved by nature as a way of experiencing our collective involvement in a disaster of planetary proportions. ${ }^{5}$ The ethical dimension of being moved comes to the fore, a point that reinforces the focus on "core values" in Cova and Deonna's (2014) and Eric Cullhed's (2019) recent conceptualizations of this emotion. From this perspective, the experience of being moved is linked to the activation of "core values": "Something very dear to you makes its appearance," in Ed Tan's (2009, p. 74) words. Being moved by natural realities that one recognizes to be fragile and entangled with human processes involves a renewed sense of ethical responsibility vis-à-vis the nonhuman. Along with underscoring the ethical investment of being moved, I explore its embodied underpinnings, which are sidelined by most theorists of being moved: the understanding of being moved I propose centers on patterned resonances between the embodied mind and the physical world. Carroll's metaphorical being moved by nature turns into an account of the primacy of movement in confronting the nonhuman world-a movement that may result in sublime feelings but involves a range of ethically infused emotions as well.

\section{Sublime materiality}

Edmund Burke's 1757 Philosophical Enquiry famously presents the sublime of natural landscapes as a result of the terror they elicit through their sheer size, especially insofar as terror blends with delight "at certain distances, and with certain modifications" (Burke, 1990, pp. 36-37). Burke sees the sublime in rigorously physiological terms, as the way in which the scale of nature vibrates in our bodies, creating an internal motion of the nerves that is subjectively experienced as emotion: 
Having considered terror as producing an unnatural tension and certain violent emotions of the nerves; it easily follows, from what we have just said, that whatever is fitted to produce such a tension, must be productive of a passion similar to terror, and consequently must be a source of the sublime, though it should have no idea of danger connected with it. So that little remains towards shewing the cause of the sublime, but to shew that the instances we have given of it in the second part, relate to such things, as are fitted by nature to produce this sort of tension, either by the primary operation of the mind or the body. (Burke, 1990, p. 121)

The physiological basis of Burke's sublime is the subject of Alan Richardson's The Neural Sublime (2010), which is part of a wave of recent scholarship seeking to reappraise the materialism of much protoRomantic and Romantic thought. ${ }^{6}$ Materialism here denotes the view that mental life, including feeling, derives from material changes in our bodies and brains, without any mentalistic residue. This reading of the sublime runs counter to a tradition of interpreting Romantic statements in an idealist vein - with emotion, including sublime feelings, affording transcendence from the physiological confines of the body. ${ }^{7}$

The question whether the sublime is read materialistically or idealistically has significant consequences for an account of being moved by nature. I turn here to the work of another scholar of Romanticism, Christopher Hitt (1999), who aims to distill a concept of the "ecological sublime." Hitt starts by noting that, curiously, even though the Romantic sublime has shaped the Western cultural imagination of the wilderness so profoundly, it has rarely received more than passing mentions within the field of ecocriticism, or environmentally oriented literary criticism. ${ }^{8}$ The reason, Hitt suggests, is that the imagination of the sublime is tied to a nature-culture dualism that, as discussed above, is still active in Carroll's work, and that has largely been superseded in the environmental humanities. 
Nevertheless, Hitt argues that it is possible to uncouple the sublime from this dualistic tradition and recover its ecological value. The villain in Hitt's story is Immanuel Kant, for whom the sublime may well begin with the emotions aroused by natural or artistic greatness, but ends up in a very different place: the sublime as articulated in Kant's Critique of Judgment culminates in an affirmation of human reason and in what Hitt calls a "traditional reinscription of humanity's supremacy over nature" (1999, p. 609). The ecological sublime, by contrast, arises when one senses the marvelous "inaccessibility of wild nature" (Hitt, 1999, p. 620), where inaccessibility denotes the failure of human language and reason to come to terms with nonhuman landscapes that transcend us in spatial scale and temporal depth. The materiality of the nonhuman world eludes our cognitive and linguistic grasp, and there is - for Hittecological and ecocritical value in this sobering realization.

In the context of today's debates on the climate crisis, Hitt's focus on "wild nature" is not entirely unproblematic: as long as the nonhuman wilderness remains the core focus of being moved by nature, the specter of dualism can never be completely eliminated. What is missing in Hitt's account is a reflection on materiality as a concept that can help overcome the nature vs. humankind binary. From a Burkean perspective, responding to nonhuman materiality is in itself a material affair-that is, it involves material happenings in our physical bodies. Burke saw these happenings as nervous tensions; today, we would see them as patterns of brain activity and neurochemical modulation. Emotions would thus be as thoroughly material as the nonhuman landscapes that are eliciting these emotions. Foregrounding the materiality of our responses to nature allows us to bring out the continuity of human bodies and nonhuman spaces, and thus challenge nature-culture binaries. Crucially, insisting on shared, patterned materiality across the human-nonhuman divide requires going beyond being moved by nature as a mere metaphor; it requires seeing movement as deeply bound up with both emotional responses and nonhuman spaces. To this end, I will cross-fertilize Maxine Sheets-Johnstone's philosophy of movement with David Abram's phenomenologically inspired ecological thinking. 


\section{Being moved by stalactites}

Maxine Sheets-Johnstone's $(1999,2011)$ seminal discussion of the link between motion and emotion has a great deal in common with the Jamesian view that emotion is the proprioceptive experience of bodily changes. ${ }^{9}$ But Sheets-Johnstone's philosophy goes further, arguing that, in addition to these bodily changes, emotion involves shifts in bodily stance toward the world, particularly shifts in the qualities of movement: contrast, for instance, the nervous fidgeting of a student before an exam with the selfconfident posture at the podium of an expert public speaker. From this phenomenological perspective, movement is integral part of the performance and experience of emotion, which is -in turn-a fundamental feature of animate bodies. In Sheets-Johnstone's words: "Being whole-body phenomena, emotions require a methodology capable of capturing kinetic form. When serious attention is turned to kinetic form and to the qualitative complexities of movement, emotions are properly recognized as dynamic forms of feeling" (1999, p. 274). Being moved is, thus, not a specific emotion but the general form of emotional experience, and it combines physiological changes with the kinetic properties of an organism's interaction with the world.

Sheets-Johnstone's focus is on animacy-that is, the movement intrinsic to living bodies. Effectively, however, by insisting on the continuum between emotional experience and physical engagement with the environment, Sheets-Johnstone's discussion creates an opportunity for seeing "being moved by nature" in terms of bodily movement: "Nature is 'a principle of motion,' as Aristotle recognized, and kinetic form is its natural expression" (Sheets-Johnstone, 1999, p. 275). The problem is understanding how such intrinsically affective movements may be directed at "kinetic forms" that do not coincide with a living organism, but with natural locations or scenes such as a forest or a waterfall. This is where David Abram's account in The Spell of the Sensuous offers valuable insights. 
Like Sheets-Johnstone, Abram writes in a phenomenological framework. His core claim is that the natural world beckons to our senses through its many forms. Abram suggests: "For the largest part of our species' existence, humans have negotiated relationships with every aspect of the sensuous surroundings, exchanging possibilities with every flapping form, with each textured surface and shivering entity that we happened to focus upon" (1997, p. ix). Yet Western conceptual categories, with their neat separation between human subjectivity and nonhuman matter, make us blind to these shifting forms and silence the call of the natural world. Also by drawing inspiration from Indigenous cultures and cosmologies, Abram wants us to recover the capacity to resonate with the nonhuman by feeling its shapes and textures.

It is important to stress that Abram is not offering a general account of the workings of perception. He is aware that not all subjects will resonate with their "sensuous surroundings." Indeed, the point of his discussion is that individuals in the Western world have largely lost that ability. But perception may be trained to maximize kinetic responses to natural environments. Such responses may build on empirically verifiable tendencies: for instance, an fMRI study of sublime experiences by Tomohiro Ishizu and Semir Zeki (2014) has revealed activity in brain areas, such as the inferior temporal cortex and the fusiform gyrus, that are involved in sensory perception. Emotion and sensory patterns go hand in hand in perceiving sublime natural scenery, even if only emotion is experienced, not its sensory underpinnings. Through an intensification of these basic neurological responses, individuals may be able to recover the sensuousness of natural environments in a more conscious way. This, at least, is the purpose of the phenomenological training envisaged by Abram.

A concrete example will help explicate this point. Consider the typical appearance of a cave rich in rock formations: an expanse of needle-thin stalactites hanging from the ceiling of the cave, along with some larger, pillar-like stalagmites. These formations are the result of rock dissolving and dripping in the space of thousands of years. The unique texture of these rocks points to the passage of geological time. Now 
let us imagine an observer who is in possession of this geological insight and perceptually attuned to the patterns of the natural world, as Abram posits. Their body will be capable of resonating with the physical shape of these calcium deposits, feeling the gravity slowly push down the limestone from the ceiling. This resonance may not be as strong as the response to the movement of other living bodies-for instance, through the activation of mirror neurons-but it will still be part and parcel of the observer's experience of the cave. ${ }^{10}$ This, I take it, is what Abram means by "exchanging possibilities with every ... form." Movement is central to that hypothetical experience-the subject's movement as they view the rocks, but also the imagined movement of the liquid limestone as it is drips from the cave's ceiling. That movement may well become bound up with marvel at the slowness of geological time, and at the difference in temporal scale between embodied existence and the trickling of soluble rock.

While this perception will likely not be shared by everyone in conscious terms, the involvement in the sublime of brain areas linked to sensuous perception (as shown by Ishizu and Zeki) suggests that there is at least a potential for such a response. If that is correct, emotional responses to the natural world are also inherently (if implicitly) material and kinetic. Drawing on phenomenological work by SheetsJohnstone and Abram puts us in a better position to understand these sublime feelings as a way of being, literally, moved by nature. The kinetic patterns of our bodies follow the kinetic contour of nonhuman spaces, and emotion arises as we perceive a scalar gap or discontinuity between these movements. ${ }^{11}$ Again, this alignment of emotional reactions to natural landscapes and sensory patterns may remain completely unconscious, and even that unconscious link is only incipiently demonstrated by Ishizu and Zeki's study: more work is needed to bolster these claims from an empirical perspective. In a more speculative vein, though, I propose that embracing kinetic feelings-as Abram teaches us to docan contribute significantly to challenging a dichotomous understanding of nature as a space external to, and separable from, human communities. The common ground between human experience and 
nonhuman realities is their materiality and their patterning - their possessing forms that, while vastly different, are still recognizably kinetic.

The cave evokes sublime feelings, but focusing on materiality and kinetic form discourages a transcendental reading of the sublime as affirming human mastery and exceptionality. We are, in other words, in the vicinity of Hitt's ecological sublime. Yet even that version of the sublime may be insufficient to capture the complexity of being moved by nature in the Anthropocene. The scalar gap foregrounded by the sublime can easily fall back on a conceptual divide separating humans from nature. To prevent that slide, we need to proceed beyond the sublime and adopt a broader range of feelings in our dealings with the nonhuman world.

\section{Falling with the walrus}

Affect is a major keyword in discussions on literature and the environment, as a recent collection edited by Kyle Bladow and Jennifer Ladino (2018) testifies. Interestingly, the sublime plays a very minor role in Bladow and Ladino's Affective Ecocriticism. Far more salient are negative feelings directed at humanity's impact on the natural world. These feelings include grief at environmental degradation and species extinction, along with the ecological anxiety sometimes referred to as "solastalgia," which is an affect of loss and displacement as a result of dramatic environmental changes. ${ }^{12}$ These are all ways in which we can be moved by nature; however, the source of these feelings - the kind of "nature" involved-is not the pristine wilderness associated with the sublime, but contaminated estuaries, depleted fields, and shrinking glaciers, places deeply scarred by human activity.

As an example of the distressing emotional impact of climate change, I will discuss an episode of the Netflix documentary series Our Planet that has garnered a great deal of attention on social media when it was released in 2019. ${ }^{13}$ Narrated by David Attenborough, Our Planet departs from most nature documentaries in that the wonders of the natural world are always shown alongside the consequences 
of anthropogenic devastation. In the episode in question, we see a large congregation of Arctic walruses on a rocky outcropping in northern Russia; suddenly, several of these walruses appear to deliberately step off the cliff and are shown tumbling down, in a long and dramatic fall to their death. The episode links this strange behavior to climate change, which has greatly reduced the number of icy platforms where walruses prefer to gather, and from where they usually jump into the water to forage for food. Because of habitat loss, the walruses are forced to spend more time on land, in increasingly large groups. These colonies, known as haul-outs, are not a new phenomenon, but the increased density of walruses and the distance from the water makes accidents like the one shown in Our Planet more and more likely. Walruses, concludes an article in The Atlantic, "can no more resist the changing of the world than they can defy gravity" (Yong, 2019).

This disturbing scene led to widespread emotion on social media. Here are some of the tweets collected by Adam Epstein (2019) in an article for the online magazine Quartz: "Burst into tears watching \#OurPlanet, that walrus scene was the most harrowing thing I've ever seen on a documentary" (@_rhiannonirving); “Attenborough's Our Planet. Spectacular and horrifying in equal measure. I will never recover from the walrus scene" (@ursulaheger). The shock and distress expressed by many viewers exemplifies the link between motion and emotion discussed by Sheets-Johnstone: their emotional response to the walruses is likely to involve a mechanism of motor resonance and reflect an instinctual acknowledgement of the creatures' animacy and physical vulnerability. (Of course, more conscious and cognitive factors may modulate this response, too: I will return to this point in a moment.) In Affective Ecologies (2017), Alexa Weik von Mossner discusses the role of motor resonance-or embodied simulation, as she calls it-in engaging with literary and cinematic representations of the ecological crisis. Weik von Mossner foregrounds the link between such resonance and empathy for nonhuman animals, and that is certainly an important element in viewing this sequence, too. It is another feeling that interests me here, however: a sense of wrongness, of weirdness, 
that accompanies the audience's realization that these animals' deadly fall is the indirect result of human activity, and particularly of industrial production within a capitalist global economy.

To be sure, this emotional reaction is mediated by scientific knowledge-more specifically, by our trusting the documentary's suggestion that this behavior can be linked to climate change and retreating ice floats. In response to the documentary, skeptics were quick to argue that this event is related to polar bear attacks, and has nothing to do with climate change. While the evidence overwhelmingly supports the explanation proposed by Our Planet, the controversy surrounding the episode demonstrates that emotions may be grounded in widely shared kinetic responses, but they are always framed and modulated by cognitive and cultural evaluations, including those involved in scientific knowledge. I mentioned above Carroll's disagreement with Carlson over the role of scientific knowledge and emotions in our engagement with nature: seeing the walruses' fall as a disturbing product of anthropogenic climate change depends on a complex interaction of affective and kinetic involvement and cultural meaning-making.

It is clear, however, that the sublime can no longer be the dominant mode of emotionally engaging with nature, because even Hitt's ecological sublime cannot fully account for the complexity of humannonhuman relations in the Anthropocene. Grief, distress, and guilt complicate and enrich the sublime: these are all emotions directed at the strange involvement of our daily actions in phenomena that our culture has taught us to construe as "natural" in the sense of external to the human. In contemporary literature, this unsettling strangeness looms large in works belonging to a strand of "New Weird" fiction (see Luckhurst, 2017) -for example, the Southern Reach trilogy by Jeff VanderMeer (2014b, 2014a, 2014c). The trilogy, which comprises Annihilation, Authority, and Acceptance, focuses on an area in Florida marked by unprecedented changes to the ecosystem due to a mysterious contamination, possibly of extraterrestrial origin. 
The sublime is certainly part of VanderMeer's imagination of Area X, particularly through its engagement with the deep temporality of life on Earth, which - the novels suggest-will survive any human-induced devastation in the long run. But this is a sublime shot through with horror, guilt, and a deep sense of incongruity, and in all these respects it is eerily reminiscent of the walruses' suicidal behavior. ${ }^{14}$ Being moved by nature in the Anthropocene thus means expanding our affective palette by experiencing "nature," between scare quotes, in all its weird complexity, including the troubling moral responsibilities of human impact on ecosystems.

I have already mentioned Cova and Deonna's (2014) and Cullhed's (2019) argument that the emotion of being moved is triggered by the activation of the experiencer's core values. My discussion has shown that this activation involves more than a cognitive process of value attribution and attachment, since it is grounded in low-level sensory and kinetic responses. In that way, my admittedly speculative account of being moved by nature bridges the gap between basic embodied engagements with the world and more sophisticated, cultural evaluations: it suggests that value attributions can be steered and modulated by the intensification of sensory attention. Learning to attune our perception to the patterns of the natural world (as discussed by Abram) affords an opportunity to reappraise our commitments and values at a more cognitive level. To be moved by nature in the Anthropocene, we need to start seeing the delicate entanglement of human societies and biological, geological, and climatological processes as "something very dear to us." To this end, it is crucial to go beyond the standard affective templates that have shaped the Western imagination of the wilderness since the Romantic period.

\section{Conclusion}

The account of being moved by nature I have developed in this article centers on the perception of patterned movement, which underlies our subjective experience of our bodies in interaction with the world but also emerges from seemingly "natural" phenomena such as the stalactites or the walruses' 
fall. In movement, the materiality of human bodies fuses with the materiality of the physical world, opening up a conduit of communication that goes beyond a merely metaphorical reading of the phrase "being moved by nature." The sublime experience of scalar discontinuity is one way in which our bodies can resonate with nonhuman phenomena, and it can be traced back to Burke's materialist account of the sublime as a matter of nervous tensions. But the sublime should not be seen as a culturally privileged way of relating to the nonhuman, because it cannot fully leave behind a sense of separation between the human subject and the wilderness. If we look beyond the retreating wilderness, we encounter a number of spaces that are being shaped, dramatically, by human activity. These spaces move us in different ways than the Romantic sublime, or in ways that vary and complicate the ecological sublime Hitt writes about, by pointing to human societies' moral and material implication with nonhuman realities.

Central to this reappraisal of being moved by nature is an understanding of emotion as an embodied happening, so that the phrase "being moved" is understood broadly, as reflecting the general workings of emotion, following Sheets-Johnstone. We can be moved by other human bodies, in the kinesthetic resonance that underlies everyday intersubjectivity, but-given the right propensities and attentional skills - we can also be moved by nonhuman animals and inanimate landscapes, or specific features thereof. Movement exists on multiple spatial and temporal scales, but the exact qualities it evokes depend on the values and cultural views that become entangled with our emotional meaning-making. Embracing the full gamut of these emotional responses offers a route into the strangeness of our Anthropocenic moment and allows us to fully come to terms with its dramatic stakes. 


\section{Acknowledgment}

While working on this article, the author has received funding from the European Research Council

(ERC) under the European Union's Horizon 2020 research and innovation program (grant agreement No 714166).

\section{Bibliography}

Abram, D. (1997). The Spell of the Sensuous: Perception and Language in a More-Than-Human World. Vintage.

Albrecht, G., Sartore, G.-M., Connor, L., Higginbotham, N., Freeman, S., Kelly, B., Stain, H., Tonna, A., \& Pollard, G. (2007). Solastalgia: The Distress Caused by Environmental Change: Australasian Psychiatry, 15(1), S95-S98.

Appleton, J. (1975). The Experience of Landscape. Wiley.

Bate, J. (2013). Romantic Ecology (Routledge Revivals): Wordsworth and the Environmental Tradition. Routledge.

Bladow, K., \& Ladino, J. (Eds.). (2018). Affective Ecocriticism: Emotion, Embodiment, Environment. University of Nebraska Press.

Buell, L. (2005). The Future of Environmental Criticism: Environmental Crisis and Literary Imagination. Blackwell.

Burke, E. (1990). A Philosophical Enquiry into the Origin of our Ideas of the Sublime and Beautiful (A. Phillips, Ed.). Oxford University Press.

Carlson, A. (2007). The Requirements for an Adequate Aesthetics of Nature. Environmental Philosophy, 4(1-2), 1-13. https://doi.org/10.5840/envirophil200741/22

Carlson, A. (2008). Nature and Landscape: An Introduction to Environmental Aesthetics. Columbia University Press. 
Carroll, N. (1993). On Being Moved by Nature: Between Religion and Natural History. In S. Kemal \& I. Gaskell (Eds.), Landscape, Natural Beauty and the Arts (pp. 244-266). Cambridge University Press.

Chakrabarty, D. (2014). Climate and Capital: On Conjoined Histories. Critical Inquiry, 41(1), 1-23.

Cova, F., \& Deonna, J. A. (2014). Being Moved. Philosophical Studies: An International Journal for Philosophy in the Analytic Tradition, 169(3), 447-466.

Crist, E. (2013). On the Poverty of Our Nomenclature. Environmental Humanities, 3(1), 129-147.

Crutzen, P. J. (2002). Geology of Mankind. Nature, 415(6867), 23.

Damasio, A. (2000). The Feeling of What Happens: Body and Emotion in the Making of Consciousness. William Heinemann.

Epstein, A. (2019, April 8). Netflix's "Our Planet" Has Made the Walrus the New Heartbreaking Image of Climate Change. Quartzy. https://qz.com/quartzy/1589570/the-story-of-that-horrifying-walrusscene-in-netflixs-our-planet/

Garrard, G. (2004). Ecocriticism. Routledge.

Goldstein, A. J. (2017). Sweet Science: Romantic Materialism and the New Logics of Life. University of Chicago Press.

Grusin, R. (Ed.). (2015). The Nonhuman Turn. University of Minnesota Press.

Haraway, D. (1991). Simians, Cyborgs and Women: The Reinvention of Nature. Routledge.

Hitt, C. (1999). Toward an Ecological Sublime. New Literary History, 30(3), 603-623.

lacoboni, M., Molnar-Szakacs, I., Gallese, V., Buccino, G., Mazziotta, J. C., \& Rizzolatti, G. (2005). Grasping the Intentions of Others with One's Own Mirror Neuron System. PLoS Biol, 3(3), 529535.

Ishizu, T., \& Zeki, S. (2014). A Neurobiological Enquiry into the Origins of Our Experience of the Sublime and Beautiful. Frontiers in Human Neuroscience, 8, 1-10. 
James, W. (1884). What Is an Emotion? Mind, 9, 188-205.

Luckhurst, R. (2017). The Weird: A Dis/orientation. Textual Practice, 31(6), 1041-1061.

Morton, T. (2010). The Ecological Thought. Harvard University Press.

Richardson, A. (2010). The Neural Sublime: Cognitive Theories and Romantic Texts. Johns Hopkins University Press.

Robertson, B. J. (2018). None of This Is Normal: The Fiction of Jeff VanderMeer. University of Minnesota Press.

Shaviro, S. (2012). Twenty-Two Theses on Nature. The Yearbook of Comparative Literature, 58(58), 205210.

Sheets-Johnstone, M. (1999). Emotion and Movement: A Beginning Empirical-Phenomenological Analysis of Their Relationship. Journal of Consciousness Studies, 6(11-12), 259-277.

Sheets-Johnstone, M. (2011). The Primacy of Movement (Expanded second edition). John Benjamins.

Slovic, S. (1992). Seeking Awareness in American Nature Writing. University of Utah Press.

Tan, E. (2009). Being Moved. In D. Sander \& K. Scherer (Eds.), Oxford Companion to Emotion and the Affective Sciences (p. 74). Oxford University Press.

Ulstein, G. (2017). Brave New Weird: Anthropocene Monsters in Jeff VanderMeer's "The Southern Reach." Concentric: Literary and Cultural Studies, 43(1), 71-96.

VanderMeer, J. (2014a). Authority. Farrar, Straus and Giroux.

VanderMeer, J. (2014b). The Southern Reach Trilogy 1: Annihilation. Farrar, Straus and Giroux.

VanderMeer, J. (2014c). The Southern Reach Trilogy 3: Acceptance. Farrar, Straus and Giroux.

Weik von Mossner, A. (2017). Affective Ecologies: Empathy, Emotion, and Environmental Narrative. Ohio State University Press.

Woods, D. (2014). Scale Critique for the Anthropocene. Minnesota Review, 83, 133-142. 
Yong, E. (2019, April 8). The Disturbing Walrus Scene in "Our Planet." The Atlantic.

https://www.theatlantic.com/science/archive/2019/04/why-are-walruses-walking-offcliffs/586510/

\footnotetext{
${ }^{1}$ See Carlson $(2007,2008)$ for a recent overview of his environmental aesthetics.

${ }^{2}$ For an influential treatment of ecological issues in Romantic poetry, see Bate's (2013) study on Wordsworth.
}

${ }^{3}$ See Scott Slovic's critical discussion of the "facile sense of harmony, even identity, with one's surroundings ... a condition often ascribed to rhapsodic nature writing" (1992, p. 4).

${ }^{4}$ For related critiques of the nature-culture divide, see Haraway (1991) and Morton (2010). See also Richard Grusin's (2015) suggestion to bring together these approaches under the heading of "nonhuman turn."

${ }^{5}$ Importantly, while it is easy to make generalizing claims about humanity's role in shaping the climate, not all human societies are equally responsible for environmental devastation. The burden of responsibility lies with developed countries, whose impact on the climate is tied to colonial and capitalist practices. See Crist (2013) for further discussion.

${ }^{6}$ See also Amanda Goldstein's Sweet Science: Romantic Materialism and the New Logics of Life (2017).

${ }^{7}$ In Richardson's words: "the sublime experiences that most interest me in poets like Keats and Shelley could best be described, not as transcendental moments or assertions of linguistic mastery over the body, nature, or the feminine but as instances of a corporeal sublime" (2010, p. 25).

${ }^{8}$ See Garrard (2004) and Buell (2005) for widely cited introductions to ecocriticism.

${ }^{9}$ See James (1884) for a first and highly influential statement of that view, which has been relaunched recently by Damasio (2000), albeit with a few terminological and conceptual differences. 
${ }^{10}$ For more on mirror neurons and their possible role in intersubjectivity, see lacoboni et al. (2005).

${ }^{11}$ Derek Woods (2014) offers a helpful discussion of scalar gaps in thinking about climate change and the Anthropocene.

12 The term “solastalgia" was coined by Glenn Albrecht. See Albrecht et al. (2007).

${ }^{13}$ I would like to thank Gry Ulstein for bringing this scene to my attention.

${ }^{14}$ For more on weird fiction and the Anthropocene, see Ulstein (2017) and Robertson (2018). 